\title{
Adaptabilidade e estabilidade de populações de milho-pipoca relacionadas por ciclos de seleção
}

\author{
Vinícius Ribeiro Faria(1), José Marcelo Soriano Viana(1), Gabriel Borges Mundim(1), Admilson da Costa e Silva(1) \\ e Tassiano Maxwell Marinho Câmara(2)
}

(1)Universidade Federal de Viçosa, Departamento de Biologia Geral, CEP 36570-000 Viçosa, MG. E-mail: virfaria@yahoo.com.br, jmsviana@ufv.br, gabriel_mundim@yahoo.com.br, admilsoncostaesilva@yahoo.com.br (2)Universidade Federal Rural da Amazônia, Campus de Capitão Poço, CEP 68650-000 Capitão Poço, PA. E-mail: tassiano.camara@ufra.edu.br

\begin{abstract}
Resumo - Os objetivos deste trabalho foram estimar os parâmetros de adaptabilidade e estabilidade em populações de milho-pipoca relacionadas por ciclos de seleção, inferir sobre a eficiência dos métodos de seleção pelos quais as populações foram obtidas e avaliar os efeitos da seleção sobre os parâmetros de adaptabilidade e estabilidade. Vinte e cinco populações e três testemunhas comerciais foram avaliadas em 14 ensaios realizados nos anos agrícolas de 2003/2004, 2004/2005, 2006/2007, 2008/2009 e 2009/2010, em sete locais. Utilizouse o delineamento experimental de blocos completos ao acaso, com quatro repetições. Foram analisadas a capacidade de expansão, avaliada em forno de microondas e na pipocadora Metric Weight Volume Tester (MWVT), além da produtividade de grãos. Utilizou-se o método de adaptabilidade e estabilidade de Eberhart \& Russell. Em geral, as populações base e melhoradas apresentaram previsibilidade de comportamento em resposta às variações de ambiente. A seleção pode provocar mudanças nos padrões de adaptabilidade e estabilidade, e as diferentes estratégias de seleção empregadas na obtenção das populações apresentaram eficiências semelhantes.
\end{abstract}

Termos para indexação: Zea mays, interação genótipo x ambiente, ganhos genéticos.

\section{Adaptability and stability of popcorn populations related through selection cycles}

\begin{abstract}
The objectives of this work were to estimate the adaptability and stability parameters of popcorn populations related through cycles of selection, to infer about the efficiency of the selection methods by which the populations were obtained and to assess the effects of selection on the parameters of adaptability and stability. Twenty-five populations and three commercial controls were evaluated in 14 trials carried out in the 2003/2004, 2004/2005, 2006/2007, 2008/2009 and 2009/2010 growing seasons, in seven locations. The experimental design used was randomized complete blocks with four replicates. The expansion volume, evaluated in a microwave oven and in the Metric Weight Volume Tester (MWVT), as well as grain yield were analyzed. The Eberhart \& Russell adaptability and stability method was used. In general the initial and improved populations showed predictable performance in response to changes in the environment. Selection can cause changes in the adaptability and stability patterns, and the different selection strategies performed in order to obtain the populations showed similar efficiencies.
\end{abstract}

Index terms: Zea mays, genotype x environment interaction, genetic gains.

\section{Introdução}

Parte da variação fenotípica de uma cultivar avaliada em diferentes ambientes provavelmente deve ser decorrente da interação genótipo x ambiente. A relevância desse fenômeno no melhoramento genético é reconhecida há anos. À medida que a correlação entre os valores fenotípico e genotípico diminui, aidentificação das populações verdadeiramente superiores fica impedida ou dificultada (Comstock \& Moll, 1963).
Apenas a análise da magnitude da variância em decorrência dos efeitos de interação não permite compreender como uma cultivar responde às variações no ambiente (Finlay \& Wilkinson, 1963) e, por isso, os estudos sobre esse fenômeno são em geral complementados com a análise de adaptabilidade e estabilidade das cultivares.

Diversos métodos paramétricos e não paramétricos foram propostos desde a década de 1960, com destaque, entre os paramétricos, para aqueles que se baseiam em regressão linear, como os de Eberhart \& Russell

Pesq. agropec. bras., Brasília, v.45, n.12, p.1396-1403, dez. 2010 
(1966) e Cruz et al. (1989). Entre os métodos não paramétricos, destacam-se os de Lin \& Binns (1988) e Annicchiarico (1992). O primeiro considera como mais adaptada e estável a cultivar que tem as menores distâncias da cultivar de melhor desempenho em cada ambiente. No segundo, adaptabilidade e estabilidade são medidas pelo índice de confiança. A cultivar mais adaptada e estável é a que apresenta a maior média das médias percentuais de desempenho, em relação à média de cada ambiente, e menor desvio padrão de médias percentuais.

Além das diferenças de processamento de dados, os métodos podem diferir quanto ao conceito de estabilidade. Lin \& Bins (1988) analisaram os conceitos de invariância de comportamento, de resposta paralela à resposta média de todas as cultivares e de previsibilidade de desempenho, e concluíram que todos têm limitações. Segundo esses autores, o primeiro, embora seja equivalente ao conceito de homeostase, não é muito empregado pelos melhoristas, pois as cultivares de comportamento constante nos ambientes são, em geral, inferiores. O segundo gera uma classificação das cultivares muito afetada pelo conjunto de populações avaliadas. O terceiro só seria realmente de valor em caso de definição de um modelo preditivo que levasse em conta os fatores do ambiente na sua quantificação, e não as cultivares estudadas.

O melhoramento genético de milho-pipoca no Brasil é ainda um processo incipiente e, por isso, os estudos de adaptabilidade e estabilidade desenvolvidos nos últimos dez anos não envolveram, além das testemunhas comerciais, populações melhoradas. Carpentieri-Pípolo et al. (2005) avaliaram, durante duas safras, em dois locais, oito populações oriundas da seleção de variedades locais do norte do Paraná, e empregaram o método de Eberhart \& Russell (1966). Em relação à produtividade de grãos e capacidade de expansão (CE), esses autores identificaram populações com ampla adaptabilidade e boa previsibilidade, com médias de produtividade de grãos que variaram entre 2.422 e $3.733 \mathrm{~kg} \mathrm{ha}^{-1}$, e médias de CE entre 22,5 e $28,6 \mathrm{~mL} \mathrm{~mL}^{-1}$.

Von Pinho et al. (2003), ao utilizar os métodos de Eberhart \& Russell (1966) e de Annicchiarico (1992), caracterizaram oito populações em 12 ambientes no estado de Minas Gerais, e detectaram interação entre populações e ambientes apenas no que se refere a produtividade de grãos. As duas metodologias indicaram que as cultivares Zélia, IAC 112 e
Ames-4198 foram superiores quanto à produtividade de grãos e CE, e apresentaram os menores riscos de cultivo. Nunes et al. (2002), utilizando os métodos de Eberhart \& Russell (1966) e de Lin \& Binns (1988), avaliaram nove populações em oito ensaios em Coimbra, MG, e concluíram que as duas metodologias foram equivalentes na discriminação das populações. Empregando os métodos de Eberhart \& Russell (1966) e Cruz et al. (1989), Vendrusculo et al. (2001) avaliaram 15 populações em 19 ambientes. Apesar de apresentarem baixos valores de CE, de 17 a $21 \mathrm{~mL} \mathrm{~mL}^{-1}$, todas as populações demonstraram boa estabilidade. Nenhuma cultivar atendeu ao conceito de genótipo ideal de Cruz et al. (1989), ou seja, alta capacidade produtiva, alta $\mathrm{CE}$, resposta linear menor que um aos ambientes desfavoráveis e maior que um aos ambientes favoráveis, e desvio da regressão estatisticamente igual a zero.

Os objetivos deste trabalho foram estimar os parâmetros de estabilidade e adaptabilidade de populações relacionadas por ciclos de seleção, inferir sobre a eficiência dos métodos de seleção pelos quais as populações foram obtidas e avaliar os efeitos da seleção sobre a adaptabilidade e a estabilidade.

\section{Material e Métodos}

Foram avaliadas 25 populações de milho-pipoca do programa de melhoramento do Departamento de Biologia Geral da Universidade Federal de Viçosa e três testemunhas comerciais. As populações base do programa são duas, denominadas Viçosa e Beija-Flor. Em relação às populações melhoradas derivadas da população Viçosa, quatro foram obtidas por seleção entre e dentro de famílias de meios-irmãos - Viçosa C1, Viçosa C2, Viçosa C3 e Viçosa C4 -, duas por seleção entre e dentro de famílias de irmãos completos - Viçosa FIC C1 e Viçosa FIC C2 -, e cinco por seleção de famílias endógamas, do programa de desenvolvimento de linhagens - Viçosa S1, Viçosa S2, Viçosa S3, Viçosa S4 e Viçosa S5. As populações derivadas de Beija-Flor incluem quatro obtidas por seleção de meios-irmãos - Beija-Flor C1, Beija-Flor C2, Beija-Flor C3 e Beija-Flor C4 - e oito geradas por seleção de famílias endógamas, também do programa de desenvolvimento de linhagens, denominadas Beija-Flor S2nsS1s (Programa 2; obtida por recombinação de famílias $\mathrm{S}_{2}$ não selecionadas, derivadas de progênies $S_{1}$ selecionadas), Beija-Flor S3nsS2s (Programa 1; obtida 
por recombinação de famílias $S_{3}$ não selecionadas, derivadas de progênies $\mathrm{S}_{2}$ selecionadas), Beija-Flor $\mathrm{S} 2$ (Programa 2), Beija-Flor S3 (Programa 1), Beija-Flor S3 (Programa 2), Beija-Flor S4 (Programas 1 e 2), Beija-Flor S5 (Programas 1 e 2) e Beija-Flor S6 (Programas 1 e 2). Os termos Programa 1 e Programa 2 apenas identificam dois conjuntos de famílias endógamas derivadas da população Beija-Flor, que foram reunidas para avaliação somente na geração $\mathrm{S}_{4}$. Nos processos seletivos empregou-se, em geral, o índice de Mulamba e Mock, com pesos 2 ou 3 para CE e 1 para produtividade de grãos. As testemunhas foram os híbridos comerciais IAC 112, do Instituto Agronômico de Campinas, e Zélia e Jade, da Pioneer.

Quatorze ensaios foram conduzidos nos anos agrícolas de 2003/2004, 2004/2005, 2006/2007, 2008/2009 e 2009/2010. Os ensaios foram desenvolvidos em sete municípios que apresentam as seguintes localizações e características edafoclimáticas: 1) Viçosa, $20^{\circ} 45^{\prime} \mathrm{S}, 42^{\circ} 52^{\prime} \mathrm{W}$, altitude de $649 \mathrm{~m}$; clima tropical de altitude, temperatura média anual de $19^{\circ} \mathrm{C}$, com variação entre 10 e $23^{\circ} \mathrm{C}$, regime hídrico com média anual de $1.200 \mathrm{~mm}$; em um Argissolo Vermelho-Amarelo; 2) Coimbra, 20 $25^{\circ} \mathrm{S}, 42^{\circ} 48^{\prime} \mathrm{W}$, altitude de $650 \mathrm{~m}$, clima tropical úmido, temperatura média anual de $19^{\circ} \mathrm{C}$, com variação entre 15 e $26^{\circ} \mathrm{C}$, regime hídrico com média anual de $1.350 \mathrm{~mm}$; em um Argissolo Vermelho-Amarelo distrófico; 3 ) Oratórios, $20^{\circ} 24^{\prime} \mathrm{S}, 42^{\circ} 54^{\prime} \mathrm{W}$, altitude de $431 \mathrm{~m}$; clima tropical úmido, temperatura média anual de $19^{\circ} \mathrm{C}$, com variação entre 14 e $26^{\circ} \mathrm{C}$, regime hídrico com média anual de $1.220 \mathrm{~mm}$; em um Argissolo Vermelho-Amarelo; 4) Capinópolis, $18^{\circ} 45^{\prime} \mathrm{S}, 49^{\circ} 30^{\prime} \mathrm{W}$, altitude de $560 \mathrm{~m}$; clima tropical temperado, temperatura média anual de $23^{\circ} \mathrm{C}$, com variação entre 17 e $30^{\circ} \mathrm{C}$, regime hídrico com média anual de $1.530 \mathrm{~mm}$; em um Latossolo Vermelho; 5) Tupaciguara, $18^{\circ} 35^{\prime} \mathrm{S}, 48^{\circ} 42^{\prime} \mathrm{W}$, altitude de $860 \mathrm{~m}$; clima tropical temperado, temperatura média anual de $22^{\circ} \mathrm{C}$, com variação entre 12 e $28^{\circ} \mathrm{C}$; regime hídrico com média anual de $1.477 \mathrm{~mm}$; em um Latossolo Vermelho-Amarelo distrófico; 6) Maringá, $23^{\circ} 21^{\prime} \mathrm{S} ; 52^{\circ} 04^{\prime} \mathrm{W}$; altitude de $510 \mathrm{~m}$; clima subtropical temperado; temperatura média anual de $21^{\circ} \mathrm{C}$, com variação entre 16 e $28^{\circ} \mathrm{C}$, regime hídrico com média anual de $1.500 \mathrm{~mm}$; em um Latossolo Vermelho; 7) Capitão Poço, $1^{\circ} 46$ ' $\mathrm{S}, 47^{\circ} 4^{\prime} \mathrm{W}$, altitude de $73 \mathrm{~m}$; clima equatorial, temperatura média anual de $26^{\circ} \mathrm{C}$, com variação entre 21 e $32^{\circ} \mathrm{C}$, regime hídrico com média anual de $1.600 \mathrm{~mm}$; em um Latossolo Amarelo. Os municipios de Viçosa, Coimbra e Oratórios pertencem à Zona da Mata de Minas Gerais. Os municípios de Capinópolis e Tupaciguara estão localizados no Triângulo Mineiro. Os muinicípios de Maringá e Capitão Poço pertencem aos Estados do Paraná e Pará, respectivamente.

O número de populações variou entre 11 e 25, uma vez que as populações de ciclo mais avançado foram gradualmente incluídas nos ensaios. Utilizouse o delineamento de blocos completos ao acaso com quatro repetições. As parcelas variaram de duas a quatro fileiras de $5 \mathrm{~m}$, espaçadas por $0,9 \mathrm{~m}$, com estande ideal de 25 plantas por fileira. Em cada parcela de 11 ensaios, foram medidos o estande final (covariável), a umidade (covariável), a produtividade de grãos $\left(\mathrm{kg} \mathrm{ha}^{-1}\right)$ e a $\mathrm{CE}$ $\left(\mathrm{mL} \mathrm{g}^{-1}\right)$.

Em outros dois testes, apenas a qualidade foi medida e, em um experimento, apenas o estande, a umidade e a produtividade de grãos foram medidos. As avaliações de CE foram realizadas em forno de microondas e na pipocadora Metric Weight Volume Tester (MWVT), (C. Cretors \& Co., Chicago, IL, EUA). Foram empregados fornos de microondas de 271 e $900 \mathrm{~W}$, com tempo programado para um min e 30 $\mathrm{s}$, com amostras de $30 \mathrm{~g}$, colocadas em sacos de papel kraft de $3 \mathrm{~L}$, e volume medido em proveta de $2.000 \mathrm{~mL}$. As amostras usadas na MWVT foram de $250 \mathrm{~g}$.

$\mathrm{Na}$ análise de adaptabilidade e estabilidade, foi empregado o método de Eberhart \& Russell (1966). As análises de variância conjuntas foram realizadas pelo procedimento GLM do SAS (SAS Institute, 2008), com correção da produtividade de grãos para $14,5 \%$ de umidade e estande ideal 25 plantas por fileira. Por causa da inclusão gradual de populações, ao longo dos anos em que foram realizados os ensaios, e também por causa da perda de dados, foram realizadas análises de variância conjuntas para $\mathrm{CE}$, avaliada em forno de microondas e na pipocadora MWVT em 13, 10, 9 e 7 ambientes, dependendo da população. Para produtividade de grãos, o número de ambientes por população foi de 11, 10, 9 e 8 . As médias ajustadas das análises conjuntas foram utilizadas na estimação dos parâmetros de adaptabilidade e estabilidade por meio do programa Genes (Cruz, 2001).

As populações com $\beta_{1}$ entre 0,75 e 1,25 foram consideradas como de adaptabilidade geral. As populações com $\beta_{1}$ abaixo e acima desse intervalo 
foram consideradas como de adaptabilidade a ambientes desfavoráveis e favoráveis, respectivamente. A não significância da variância dos desvios da regressão $\left(\sigma_{\mathrm{d}}^{2}\right)$ foi considerada como critério de estabilidade.

\section{Resultados e Discussão}

As análises de variância evidenciaram interação cultivar $\mathrm{x}$ ambiente e diferenças entre médias de cultivares e de ambientes em relação às duas medidas de qualidade e à produtividade de grãos (Tabela 1), o que revela adequação de um estudo de adaptabilidade e estabilidade. Os valores de CV, 8,8 a 10,3\% para CE, e 20,2 a $22,8 \%$, para produtividade de grãos, indicam excelente precisão experimental.

As populações Viçosa e Beija-Flor foram avaliadas nos diferentes subconjuntos de ambientes e seus parâmetros foram apresentados repetidas vezes para que as comparações com as populações de ciclo mais avançado fossem realizadas dentro do mesmo subconjunto (Tabela 2).

Em geral, as populações base e melhoradas apresentaram desvio da regressão $\left(\sigma^{2}{ }_{d}\right)$ não significativo, o que indica previsibilidade de resposta às variações ambientais (Tabela 2). Em relação às populações originais, analisadas nos diferentes subconjuntos de ambientes, apenas Beija-Flor, avaliada em 13 ambientes, apresentou desvio de regressão significativo para produtividade de grãos.

Entre as populações derivadas de Viçosa, quanto à CE avaliada na pipocadora MWVT, apenas Viçosa S4 foi pouco previsível. Viçosa C2 e Viçosa S2 apresentaram desvio da regressão significativo para $\mathrm{CE}$ avaliada em forno de microondas, e Viçosa C4 e Viçosa FIC C1 apresentaram desvio da regressão significativo para produtividade de grãos. Das populações derivadas de Beija-Flor, somente Beija-Flor S3nsS2s mostrou-se pouco previsível quanto às três características avaliadas. Quanto às duas medidas de qualidade, a população Beija-Flor S2 também apresentou $\sigma_{d}^{2}$ significativo. A previsibilidade de resposta linear ao ambiente, então, pode ser alterada pela seleção.

A obtenção de populações melhoradas por seleção de meios-irmãos a partir da população Viçosa promoveu mudanças nos padrões de adaptabilidade

Tabela 1. Análises de variância conjuntas da capacidade de expansão de cultivares de milho-pipoca, avaliada na pipocadora MWVT e em forno microondas e da produtividade de grãos.

\begin{tabular}{|c|c|c|c|c|c|c|c|c|}
\hline \multirow[t]{2}{*}{ Fonte de variação } & \multicolumn{2}{|r|}{ Treze ambientes } & \multicolumn{2}{|r|}{ Dez ambientes } & \multicolumn{2}{|c|}{ Nove ambientes } & \multicolumn{2}{|c|}{ Sete ambientes } \\
\hline & GL & QM & GL & QM & GL & QM & GL & QM \\
\hline & \multicolumn{8}{|c|}{ Capacidade de expansão em MWVT (mL g-1) } \\
\hline Blocos/ambientes & 39 & 18,5185 & 30 & 23,1025 & 27 & 23,6627 & 21 & 25,6987 \\
\hline Cultivar (C) & 12 & $91,2053 * * *$ & 16 & $33,1046 * * *$ & 25 & $23,6697 * * *$ & 27 & $23,7287 * * *$ \\
\hline Ambiente (A) & 12 & $53,9314 * * *$ & 9 & $65,4950 * * *$ & 8 & $109,4143^{* * *}$ & 6 & $128,2579 * * *$ \\
\hline Interação CxA & 143 & $14,8579 * * *$ & 143 & $13,4618 * *$ & 198 & $13,0935^{* *}$ & 160 & $13,2210^{*}$ \\
\hline$\underline{\text { Resíduo }}$ & 455 & 8,9016 & 465 & 9,2169 & 647 & 9,6425 & 539 & 10,5013 \\
\hline \multirow[t]{2}{*}{$\mathrm{CV}(\%)$} & & 9,53 & & 9,65 & & 9,90 & & 10,31 \\
\hline & \multicolumn{8}{|c|}{ Capacidade de expansão em forno de forno microondas $\left(\mathrm{mL} \mathrm{g}^{-1}\right)$} \\
\hline Blocos/ambientes & 39 & 5,2902 & 30 & 5,9792 & 27 & 7,4998 & 21 & 5,6002 \\
\hline Cultivar $(\mathrm{C})$ & 12 & $76,1900 * * *$ & 16 & $38,2647 * * *$ & 25 & $33,4960 * * *$ & 27 & $21,6559 * * *$ \\
\hline Ambiente (A) & 12 & $319,8190 * * *$ & 9 & $386,6241 * * *$ & 8 & $523,0008 * * *$ & 6 & $82,8713 * * *$ \\
\hline Interação CxA & 143 & $16,4563 * * *$ & 143 & $14,2030 * * *$ & 199 & $15,1103 * * *$ & 161 & $13,7027 * *$ \\
\hline$\underline{\text { Resíduo }}$ & 455 & 9,2114 & 465 & 9,3520 & 650 & 9,8704 & 541 & 9,4298 \\
\hline \multirow[t]{3}{*}{$\mathrm{CV}(\%)$} & & 8,91 & & 8,81 & & 8,96 & & 9,02 \\
\hline & & Onze ambientes & & Dez ambientes & & ve ambientes & & to ambientes \\
\hline & \multicolumn{8}{|c|}{ Produtividade de grãos $\left(\mathrm{kg} \mathrm{ha}^{-1}\right)$} \\
\hline Blocos/ambientes & 33 & $562.228,90$ & 30 & $693.257,10$ & 27 & $1.023 .217,10$ & 24 & $1.115 .705,20$ \\
\hline Cultivar (C) & 12 & $789.030,20 * * *$ & 16 & $759.040,80 * * *$ & 25 & $543.901,20 * * *$ & 27 & $548.006,90 * * *$ \\
\hline Ambiente (A) & 10 & $14.698 .372,30 * * *$ & 9 & $21.868 .363,90 * * *$ & 8 & $17.331 .763,10^{* * *}$ & 7 & $20.707 .488,40 * * *$ \\
\hline Interação CxA & 118 & $360.700,60 * * *$ & 143 & $257.415,70 *$ & 199 & $265.575,20 * *$ & 188 & $295.249,40 * * *$ \\
\hline Resíduo & 378 & $227.332,80$ & 463 & $209.884,30$ & 648 & $196.209,00$ & 621 & $208.395,00$ \\
\hline $\mathrm{CV}(\%)$ & & 22,78 & & 21,58 & & 20,25 & & 20,72 \\
\hline
\end{tabular}

$*, * *$ e $* * *$ Significativo a 5,1 e $0,1 \%$ de probabilidade respectivamente. 
das populações de ciclo avançado. Quanto à CE avaliada na pipocadora MWVT, a população original apresentou adaptabilidade a ambientes desfavoráveis nos três subconjuntos de ambientes avaliados. Entre as populações melhoradas, as de ciclo 1 e 4 passaram a ser responsivas aos estímulos ambientais, com adaptação a ambientes favoráveis (Tabela 2). Em relação à $\mathrm{CE}$ avaliada em forno de microondas, a população original foi de adaptabilidade geral. Esse padrão se manteve até a população de ciclo 3 , já que Viçosa $\mathrm{C} 4$ apresentou adaptabilidade a ambientes desfavoráveis. No que se refere à produtividade de grãos, Viçosa apresentou coeficiente $\beta_{1}$ próximo de um, indicando adaptabilidade geral. A partir da população de ciclo 2, houve mudança no padrão e as populações revelaram-se adaptadas a ambientes favoráveis.

O melhoramento populacional empregando famílias de irmãos completos também provocou alterações na adaptabilidade (Tabela 2). Quanto à CE avaliada na pipocadora MWVT, as populações melhoradas de ciclo 1 e 2 apresentaram $\beta_{1}$ maior que 1,25 , indicando adaptabilidade a ambientes favoráveis. Em relação à $\mathrm{CE}$ avaliada, em forno de microondas, a população Viçosa FIC C1 passou a apresentar adaptabilidade específica a ambientes desfavoráveis. Quanto à produtividade de

Tabela 2. Parâmetros de adaptabilidade e estabilidade estimados pelo método de Eberhart \& Russell (1966), em relação à produtividade de grãos e da capacidade de expansão (CE) avaliada na pipocadora MWVT e em forno de microondas, das populações base Beija-Flor e Viçosa, das populações melhoradas e das testemunhas ${ }^{(1)}$.

\begin{tabular}{|c|c|c|c|c|c|c|c|c|c|}
\hline \multirow[t]{2}{*}{ População } & \multicolumn{3}{|c|}{ CE em MWVT $\left(\mathrm{mL} \mathrm{g}^{-1}\right)$} & \multicolumn{3}{|c|}{$\mathrm{CE}$ em forno microondas $\left(\mathrm{mL} \mathrm{g}^{-1}\right)$} & \multicolumn{3}{|c|}{ Produtividade de grãos $\left(\mathrm{kg} \mathrm{ha}^{-1}\right)$} \\
\hline & $\beta_{0}$ & $\beta_{1}$ & $\sigma_{\mathrm{di}}^{2}$ & $\beta_{0}$ & $\beta_{1}$ & $\sigma_{\mathrm{di}}^{2}$ & $\beta_{0}$ & $\beta_{1}$ & $\sigma_{\mathrm{di}}^{2}$ \\
\hline Beija-Flor & $30,09(13)$ & 1,576 & $-0,795$ & $33,24(13)$ & 1,034 & 1,446 & $2.034(11)$ & 0,826 & $81.156^{*}$ \\
\hline Beija-Flor & $30,63(10)$ & 1,622 & $-0,846$ & $34,50(10)$ & 0,696 & 0,859 & $1.982(10)$ & 1,020 & -16728 \\
\hline Beija-Flor & $30,68 \quad(7)$ & 2,018 & $-2,180$ & $34,10 \quad(7)$ & 2,623 & $-1,452$ & $2.051(8)$ & 0,913 & -36.503 \\
\hline Beija-Flor C1 & $31,64(13)$ & 0,927 & 0,777 & $33,80(13)$ & 1,357 & 0,390 & $2.219(11)$ & 1,096 & 12.967 \\
\hline Beija-Flor C2 & $31,07(13)$ & 0,507 & 0,073 & $33,08(13)$ & 1,002 & 0,915 & $2.204(11)$ & 0,888 & 11.250 \\
\hline Beija-Flor C3 & $31,36(10)$ & $-0,227$ & $-0,085$ & $34,65(10)$ & 1,187 & $-0,120$ & $2.084(10)$ & 1,149 & 5.358 \\
\hline Beija-Flor C4 & $32,02 \quad(7)$ & 1,131 & $-1,472$ & $34,54 \quad(7)$ & 1,705 & 0,688 & $2.067(8)$ & 0,597 & 14.407 \\
\hline Beija-Flor S2nsS1s & $30,12(13)$ & 1,541 & $-0,667$ & $33,53(13)$ & 1,334 & 0,339 & $1.716(11)$ & 0,535 & 47.203 \\
\hline Beija-Flor S3nsS2s & $30,33(13)$ & 1,673 & $5,890 * *$ & $33,56(13)$ & 1,123 & $2,984 * *$ & $1.950(11)$ & 0,943 & $103.661 * *$ \\
\hline Beija-Flor S2 & $30,84(13)$ & 1,460 & $7,327 * *$ & $33,38(13)$ & 0,369 & $3,634 * *$ & $2.221(11)$ & 1,010 & 12.809 \\
\hline Beija-Flor S3 & $30,75(13)$ & 0,666 & $-1,949$ & $33,85(13)$ & 1,186 & 0,306 & $1.922(11)$ & 1,042 & 4.656 \\
\hline Beija-Flor S3 & $31,42(13)$ & 2,044 & $-0,722$ & $34,27(13)$ & 1,091 & $-0,641$ & $2.130(11)$ & 1,010 & -25.440 \\
\hline Beija-Flor S4 & $32,01(10)$ & 0,527 & $-1,063$ & $34,41(10)$ & 1,038 & $-1,795$ & $2.109(10)$ & 1,121 & 9.115 \\
\hline Beija-Flor S5 & $30,51(10)$ & 1,074 & 0,876 & $33,64(10)$ & 0,978 & $-0,820$ & $2.024(10)$ & 1,119 & -25.965 \\
\hline Beija-Flor S6 & $31,51(10)$ & 1,437 & 0,270 & $34,70(10)$ & 0,970 & $-0,129$ & $2.106(10)$ & 0,856 & -15.106 \\
\hline Viçosa & $30,48(13)$ & 0,460 & 0,417 & $33,47(13)$ & 1,016 & $-0,461$ & $2.051(11)$ & 0,855 & -24.315 \\
\hline Viçosa & $31,05 \quad(9)$ & 0,438 & $-2,008$ & $34,51 \quad(9)$ & 1,037 & 0,265 & $2.157(9)$ & 0,844 & -16.347 \\
\hline Viçosa & $31,26 \quad(7)$ & 0,390 & $-0,341$ & $33,59 \quad(7)$ & 0,799 & $-0,198$ & $2.188(8)$ & 0,814 & -11.533 \\
\hline Viçosa C1 & $30,68(13)$ & 1,448 & $-1,191$ & $34,03(13)$ & 0,862 & $-0,979$ & $2.115(11)$ & 1,160 & 37.052 \\
\hline Viçosa C2 & $31,08(13)$ & 0,721 & $-1,183$ & $33,38(13)$ & 0,787 & $2,084 *$ & $1.976(11)$ & 1,271 & -18.567 \\
\hline Viçosa C3 & $30,98 \quad(9)$ & 0,637 & $-0,825$ & $34,58 \quad(9)$ & 1,245 & $-0,487$ & $2.158(9)$ & 1,436 & -38.292 \\
\hline Viçosa C4 & $29,36 \quad(7)$ & 1,649 & 2,758 & $34,21 \quad(7)$ & $-0,057$ & 1,120 & $2.427(8)$ & 1,476 & $135.255^{* *}$ \\
\hline Viçosa FIC C1 & $32,22 \quad(9)$ & 1,256 & $-1,221$ & $34,52 \quad(9)$ & 0,189 & 2,322 & $2.212(9)$ & 0,818 & $85.551^{* *}$ \\
\hline Viçosa FIC C2 & $30,03 \quad(9)$ & 1,953 & $-0,483$ & $34,70 \quad(9)$ & 1,188 & 1,309 & $2.422(9)$ & 1,295 & 7.248 \\
\hline Viçosa S1 & $31,08 \quad(9)$ & 1,166 & $-1,501$ & $35,50 \quad(9)$ & 0,740 & 2,031 & $2.158(9)$ & 0,749 & 7.882 \\
\hline Viçosa S2 & $31,43 \quad(9)$ & 0,446 & 0,326 & $35,62 \quad(9)$ & 1,531 & $5,165^{* *}$ & $2.106(9)$ & 1,439 & -185 \\
\hline Viçosa S3 & $31,11 \quad(9)$ & 2,012 & 0,162 & $34,52 \quad(9)$ & 1,233 & 0,452 & $2.071(9)$ & 0,720 & -2.084 \\
\hline Viçosa S4 & $30,72 \quad(9)$ & 1,687 & $4,974 * *$ & $34,84 \quad(9)$ & 1,323 & 2,032 & $1.956(9)$ & 0,735 & -977 \\
\hline Viçosa S5 & $29,95 \quad(9)$ & 1,042 & $-0,864$ & $33,70 \quad(9)$ & 1,223 & $-0,323$ & $2.029(9)$ & 1,138 & -28.176 \\
\hline IAC 112 & $34,63(13)$ & $-0,226$ & $3,732 * *$ & $37,67(13)$ & 1,236 & $5,988 * *$ & 2.189 (11) & 1,046 & $82.315^{*}$ \\
\hline Zélia & $33,45(13)$ & 0,203 & $1,837 *$ & $35,11(13)$ & 0,604 & 1,233 & $2.282(11)$ & 1,318 & 39.200 \\
\hline Jade & $32,13 \quad(9)$ & 0,089 & 0,357 & $37,15 \quad(9)$ & 0,836 & 0,418 & $2.258(9)$ & 1,196 & $84.222 * *$ \\
\hline
\end{tabular}

${ }^{(1)} \beta_{0}$, média. Valores entre parênteses referem-se ao número de ambientes que originou cada média. * e **Significativo a 5 e a $1 \%$ de probabilidade, respectivamente, pelo teste $\mathrm{F}$. 
grãos, houve mudança apenas na população de ciclo 2 , que apresentou adaptação a ambientes favoráveis.

Entre as populações originadas da seleção de famílias endógamas de Viçosa, houve grande variação quanto ao parâmetro de adaptabilidade $\beta_{1}$ (Tabela 2). Para CE avaliada na pipocadora MWVT, as populações Viçosa S1 e Viçosa S5 apresentaram adaptabilidade geral, enquanto Viçosa S3 e Viçosa S4 mostraram-se adaptadas a ambientes favoráveis. Em relação à $\mathrm{CE}$ avaliada em forno de microondas, as populações de ciclo 2 e 4 diferiram da original, apresentando adaptação a ambientes favoráveis. Já Viçosa S1 mostrou-se adaptada a ambientes desfavoráveis. Quanto à produtividade de grãos, a população de ciclo 2 se mostrou adaptada aos melhores ambientes, ao passo que Viçosa S3 e Viçosa S4 se diferenciaram da original por apresentarem adaptação a ambientes desfavoráveis.

Em relação às populações originadas da seleção de meios-irmãos de Beija-Flor, percebe-se que, quanto à $\mathrm{CE}$ avaliada na pipocadora MWVT, todas tiveram comportamento diferenciado da população original (Tabela 2), o que evidencia, assim, a influência da seleção sobre a adaptabilidade. Em relação à $\mathrm{CE}$ avaliada em forno de microondas, a população original apresentou desempenhos diferentes nos três subconjuntos de ambientes. Ao se comparar as populações melhoradas com a original, no mesmo subconjunto, verifica-se mudança no padrão de adaptabilidade das populações de ciclo 1 e 3 . $\mathrm{Na}$ produtividade de grãos, a seleção promoveu pouca influência sobre a adaptabilidade das populações. Apenas Beija-Flor C4 diferiu da população original, apresentando $\beta_{1}$ menor que 0,75 .

A obtenção de populações a partir da seleção de famílias endógamas originadas de Beija-Flor também promoveu mudanças no padrão de adaptabilidade da população original (Tabela 2). Para CE avaliada na pipocadora MWVT, as populações Beija-Flor S3 (Programa 1) e Beija-Flor S4, que apresentam adaptabilidadeaambientesdesfavoráveis, eBeija-FlorS5, de adaptabilidade geral, diferem da população original e das demais populações melhoradas, que apresentam $\beta_{1}$ maior que 1,25 . Em relação à qualidade avaliada em forno de microondas, as populações melhoradas também foram comparadas com a original apenas nos ambientes comuns. Entre as populações avaliadas em 13 ambientes, a Beija-Flor S2nsS1s apresentou-se adaptada a ambientes favoráveis, enquanto Beija-Flor S2 mostrou-se adaptada a ambientes desfavoráveis. As demais populações melhoradas e a original apresentaram adaptabilidade geral nos 13 ambientes. As populações de ciclo mais avançado $(4,5$ e 6$)$ foram avaliadas em dez ambientes e todas apresentaram adaptabilidade geral, contrastando com a original, que, nos dez ambientes, se mostrou adaptada a ambientes desfavoráveis. Quanto à produtividade de grãos, a população original e a maioria das populações melhoradas apresentaram adaptabilidade geral. A única exceção foi Beija-Flor S2nsS1s que mostrou adaptação a ambientes desfavoráveis.

As populações Beija-Flor e Viçosa fizeram parte dos estudos de Miranda et al. (2009) e de Nunes et al. (2002). Em ambos estudos, a população Viçosa apresentou adaptação geral e boa previsibilidade, tanto para $\mathrm{CE}$, avaliada em pipocadora elétrica desenvolvida pela Embrapa Instrumentação Agropecuária, quanto para produtividade de grãos. Já a população Beija-Flor se mostrou adaptada a ambientes favoráveis quanto à produtividade de grãos e adaptação geral para CE. Quanto à estabilidade, demonstrou-se pouco previsível para CE.

Em relação à população Beija-Flor, a seleção de famílias de meio-irmãos ao longo de quatro ciclos promoveu um acréscimo de duas unidades na $\mathrm{CE}$ avaliada em pipocadora MWVT e de $1,2 \mathrm{~mL} \mathrm{~g}^{-1}$ na CE avaliada em forno de microondas. Isso corresponde a 1,7 e $0,9 \%$ de ganho por ciclo de seleção. Em relação à produtividade de grãos, a população Beija-Flor C4 apresentou média superior em $130 \mathrm{~kg} \mathrm{ha}^{-1}$, o que corresponde a um ganho de 1,6\% por ciclo de seleção. Na população Viçosa, a seleção de famílias de meio-irmãos promoveu um acréscimo de $0,6 \mathrm{~mL} \mathrm{~g}^{-1}$ na média de CE avaliada na pipocadora MWVT da população Viçosa C2, em comparação com a média da população original, com ganho de $0,98 \%$ por ciclo. Em relação à $\mathrm{CE}$ avaliada em forno de microondas, o ganho total em três ciclos de seleção foi de $1,1 \mathrm{~mL} \mathrm{~g}^{-1}$, que equivale a $1,1 \%$ por ciclo. Quanto à produtividade de grãos, três ciclos de seleção proporcionaram um acréscimo de $182 \mathrm{~kg} \mathrm{ha}^{-1}$, ou 2,6\% por ciclo.

Viana (2007), ao utilizar os testes dos quatro primeiros ciclos de seleção entre e dentro de famílias de meio-irmãos e quatro ensaios de competição com populações melhoradas originadas de Beija-Flor, verificou ganho realizado médio em $\mathrm{CE}$ de 5,6\%, até o terceiro ciclo de seleção. Em relação ao ganho médio em produtividade de grãos, até o terceiro ciclo, foi registrado um valor de $8,1 \%$. Os menores valores de ganho genético observados neste trabalho se devem ao fato de terem sido obtidos com base nas médias 
de sete a 13 ambientes (locais e anos), nos quais as populações foram avaliadas em pequenas parcelas experimentais. No trabalho de Viana (2007), os ganhos foram computados com base nas médias de populações representadas por 196 famílias, avaliadas no mesmo local durante três anos.

Em relação à seleção de famílias endógamas de Beija-Flor, a população Beija-Flor S5 apresentou média $1,42 \mathrm{~mL} \mathrm{~g}^{-1}$ superior à população original, para $\mathrm{CE}$ avaliada na pipocadora MWVT. Quanto à CE avaliada em forno de microondas, o aumento em relação à população original foi de $1,3 \mathrm{~mL} \mathrm{~g}^{-1}$. Esses valores correspondem a ganhos de 0,94 e $0,78 \%$ por ciclo. Ao se considerar a produtividade de grãos, o ganho foi de $110 \mathrm{~kg} \mathrm{ha}^{-1}$, ou 1,09\% por ciclo. A seleção de famílias endógamas de Viçosa proporcionou incremento de $1,0 \mathrm{~mL} \mathrm{~g}^{-1}$ na média da população Viçosa $\mathrm{S} 2$, em relação à CE avaliada em MWVT com ganho de $1,64 \%$ por ciclo. Quanto à $\mathrm{CE}$ avaliada em forno de microondas, o ganho total foi de $2,2 \mathrm{~mL} \mathrm{~g}^{-1}$, correspondente a $3,3 \%$ por ciclo. Ao se considerar a produtividade de grãos, também houve acréscimo na média da população melhorada de cerca de $130 \mathrm{~kg} \mathrm{ha}^{-1}$, um ganho de 3,16\% por ciclo de seleção.

Com o objetivo de avaliar a eficiência de diversos processos seletivos de famílias endógamas da população Beija-Flor, Vilarinho et al. (2002) encontraram, para seleção de 30 famílias $S_{1}$ e $S_{2}$, ganhos preditos com seleção direta em CE avaliada em pipoqueira de ar quente de 1,08 e $0,82 \mathrm{~mL} \mathrm{~g}^{-1}$. Daros et al. (2004) demonstraram que a seleção de famílias $\mathrm{S}_{1}$ superiores na população UNB-2U, realizada com base no índice clássico de Smith e Hazel, (Smith, 1936; Hazel, 1943) proporcionou ganhos preditos de $17,8 \%$ em CE, e de $26,95 \%$ em produtividade de grãos.

Maiores diferenças em relação às médias da população Viçosa foram observadas nas populações originadas da seleção de famílias de irmãos completos. Quanto à CE avaliada na pipocadora MWVT, a população Viçosa FIC C1 apresentou média $1,8 \mathrm{~mL} \mathrm{~g}^{-1}$ superior à original, correspondendo a um ganho de 5,9\%. Para CE avaliada em forno de microondas, o ganho em dois ciclos foi de $1,3 \mathrm{~mL} \mathrm{~g}^{-1}$ ou $1,94 \%$ por ciclo. Em relação à produtividade de grãos, ocorreu um aumento considerável na média da população Viçosa FIC C2, que apresentou produtividade de $350 \mathrm{~kg} \mathrm{ha}^{-1}$ superior à Viçosa, o que representa um ganho em produtividade de $8,42 \%$ por ciclo. Freitas Júnior et al. (2009), por meio do índice de Mulamba e Mock
(Mulamba \& Mock, 1978) na seleção de famílias de irmãos completos da população UNB-2U, estimaram ganhos de 10,55 e $8,5 \%$ para $\mathrm{CE}$ e produtividade de grãos, respectivamente.

Quanto ao potencial das populações melhoradas, como cultivares e para obtenção de linhagens, os valores médios de CE variaram de 29,4 a 32,0 $\mathrm{mL} \mathrm{g}^{-1}$, quando avaliada na pipocadora MWVT, e de 33,1 a $35,6 \mathrm{~mL} \mathrm{~g}^{-1}$, quando avaliada em forno de microondas (Tabela 2). O valor mínimo de CE sugerido por Scapim et al. (2010) para que um material tenha mérito comercial é de $30 \mathrm{~mL} \mathrm{~g}^{-1}$. Os valores médios de produtividade de grãos variaram entre $1.716 \mathrm{e}$ $2.427 \mathrm{~kg} \mathrm{ha}^{-1}$. A CE das populações estudadas por Carpentieri-Pipolo et al. (2005), avaliada em forno de microondas, variou de 22,5 e $28,6 \mathrm{~mL} \mathrm{~cm}^{-3}$. $\mathrm{Na}$ produtividade de grãos, as médias variaram de 2.421 a $3.733 \mathrm{~kg} \mathrm{ha}^{-1}$. A fim de identificar compostos com potencial de melhoramento no Brasil, Scapim et al. (2010) encontraram valores médios de $25,7 \mathrm{~mL}$ $\mathrm{g}^{-1}$ para CE avaliada na pipocadora da Embrapa Instrumentação Agropecuária e de $2.128 \mathrm{~kg} \mathrm{ha}^{-1}$ para produtividade de grãos. No estudo de Von Pinho et al. (2003), os híbridos Zélia, IAC 112 e AMES-4198 se destacaram em relação à $\mathrm{CE}$ medida em pipoqueira de ar quente, com médias de $28,6,27,6$ e $27,5 \mathrm{~mL} \mathrm{~mL}^{-1}$. Esses materiais também apresentaram as maiores produtividades, com médias de $2.710,2.728$ e $2.696 \mathrm{~kg} \mathrm{ha}^{-1}$, respectivamente.

\section{Conclusões}

1. Em geral as populações base e melhoradas apresentaram comportamento previsível em resposta às variações no ambiente.

2. A seleção pode provocar mudanças nos padrões de estabilidade e adaptabilidade.

3. As diferentes estratégias de seleção empregadas na obtenção das populações apresentaram eficiências semelhantes.

4. As populações melhoradas apresentam valor comercial e potencial para extração de linhagens.

\section{Agradecimentos}

À Fundação de Amparo à Pesquisa de Minas Gerais, à Coordenação de Aperfeiçoamento de Pessoal de Nível Superior e ao Conselho Nacional de Desenvolvimento Científico e Tecnológico, pelo auxílio financeiro. 


\section{Referências}

ANNICCHIARICO, P. Cultivar adaptation and recommendation from alfafa trials in Northern Italy. Journal of Genetics and Breeding, v.46, p.269-278, 1992.

CARPENTIERI-PÍPOLO, V.; RINALDI, D.A.; LIMA, V.E.N. de. Adaptabilidade e estabilidade de populações de milho-pipoca. Pesquisa Agropecuária Brasileira, v.40, p.87-90, 2005.

COMSTOCK, R.E.; MOLL, R.H. Genotype-environment interactions. In: HANSON, H.D.; ROBINSON, H.F. (Ed.). Statistical genetics and plant breeding. Washington: National Academy of Sciences, 1963. p.164-196. (Publication, 982).

CRUZ, C.D. Programa GENES: versão Windows: aplicativo computacional em genética e estatística. Viçosa: UFV, 2001. 642p.

CRUZ, C.D.; TORRES, R.A. de A.; VENCOVSKY, R. An alternative approach to the stability analysis proposed by Silva and Barreto. Revista Brasileira de Genética, v.12, p.567-80, 1989.

DAROS, M.; AMARAL JÚNIOR, A.T. do; PEREIRA, M.G.; SANTOS, F.S.; GABRIEL, A.P.C.; SCAPIM, C.A.; FREITAS JÚNIOR, S. de P.; SILVÉRIO, L. Recurrent selection in inbred popcorn families. Scientia Agricola, v.61, p.609-614, 2004.

EBERHART, S.A.; RUSSELL, W.A. Stability parameters for comparing varieties. Crop Science, v.6, p.36-40, 1966.

FINLAY, K.W.; WILKINSON, G.N. The analysis of adaptation in a plant-breeding programme. Australian Journal of Agricultural Research, v.14, p.742-754, 1963.

FREITAS JÚNIOR, S. de P.; AMARAL JÚNIOR, A.T. do; RANGEL, R.M.; VIANA, A.P. Predição de ganhos genéticos na população de milho pipoca UNB-2U sob seleção recorrente utilizando-se diferentes índices de seleção. Ciências Agrárias, v.30, p.803-814, 2009.

HAZEL, H.N. The genetic basis for constructing selection indexes. Genetics, v.28, n.6, 476-490, 1943.

LIN, C.S.; BINNS, M.R. A superiority measure of cultivar performance for cultivar $\mathrm{x}$ location data. Canadian Journal of Plant Science, v.68, p.193-198, 1988.
MIRANDA, G.V.; SOUZA, L.V. de; GUIMARÃES, L.J.M.; NAMORATO, H.; OLIVEIRA, L.R.; SOARES, M.O. Multivariate analyses of genotype $\mathrm{x}$ environment interaction of popcorn. Pesquisa Agropecuária Brasileira, v.44, p.45-50, 2009.

MULAMBA, N.N.; MOCK, J.J. Improvement of yield potential of the Eto Blanco maize (Zea mays L.) population by breeding for plant traits. Egypt Journal of Genetics and Cytology, v.7, p.40$51,1978$.

NUNES, H.V.; MIRANDA, G.V.; GALVÃO, J.C.S.; SOUZA, L.V. de; GUIMARÃES, L.J.M. Adaptabilidade e estabilidade de cultivares de milho-pipoca por meio de dois métodos de classificação. Revista Brasileira de Milho e Sorgo, v.1, p.78-88, 2002.

SAS INSTITUTE. SAS/STAT user's guide: statistics. Versão 9.2 Cary: SAS Institute, 2008.

SCAPIM, C.A.; JÚNIOR, A.T. do A.; VIEIRA, R.A.; MOTERLE L.A.; TEIXEIRA, L.R.; VIGANÓ, J.; SANDOVAL JÚNIOR, G.B. Novos compostos de milho-pipoca para o Brasil. Ciências Agrárias, v.31, p.321-330, 2010.

SMITH, H.F. A discriminant function for plant selection. Annals of Eugenics, v.7, p.240-250, 1936.

VENDRUSCOLO, E.C.G.; SCAPIM, C.A.; PACHECO, C.A.P.; OLIVEIRA, V.R. de; BRACCINI, A. de L.; GONÇALVES-VIDIGAL, M.C. Adaptabilidade e estabilidade de cultivares de milho-pipoca na região centro-sul do Brasil. Pesquisa Agropecuária Brasileira, v.36, p.123-130, 2001.

VIANA, J.M.S. Melhoramento intrapopulacional recorrente de milho-pipoca, com famílias de meios-irmãos. Revista Brasileira de Milho e Sorgo, v.6, p.199-210, 2007.

VILARINHO, A.A.; VIANA, J.M.S.; CÂMARA, T.M.M; SANTOS, J.F. dos. Seleção de progênies endogâmicas $S_{1}$ e $S_{2}$ em um programa de melhoramento intrapopulacional de milho pipoca. Acta Scientiarum, v.24, p.1419-1425, 2002.

VON PINHO, R.G.; BRUGNERA, A.; PACHECO, C.A.P.; GOMES, M. de S. Estabilidade de cultivares de milho-pipoca em diferentes ambientes, no estado de Minas Gerais. Revista Brasileira de Milho e Sorgo, v.2, p.53-61, 2003.

Recebido em 7 de setembro de 2010 e aprovado em 24 de novembro de 2010 